\title{
Economic aspects of modern environmental policy issues: a step forward
}

\author{
D. Damigos \& D. Kaliampakos \\ Laboratory of Mining and Environmental Technology, \\ School of Mining and Metallurgical Engineering, \\ National Technical University of Athens, Greece
}

\begin{abstract}
This paper deals with the "era of economics" in European environmental policy. Towards this direction, certain legislative requirements and strategies that promote economic issues within the EU are provided, through some illustrative examples. From the analysis, it becomes evident that there is a growing attempt in the EU to more systematically incorporate economic information in private and especially public decision-making. However, original valuation studies are both costly and time-consuming. Thus, in some cases, especially when there is limited experience, the Benefit Transfer technique may be adopted. Bearing in mind these remarks, this paper introduces an interactive benefit transfer tool, which is currently being developed. This tool, called GEVAD, will facilitate the valuation of environmental impacts in monetary terms, supporting decision-making processes in various levels within Europe.

Keywords: environmental economics, policy, legislation, project appraisal, liability, benefit transfer.
\end{abstract}

\section{Introduction}

The development of European Union (EU) environmental policy has a history of almost four decades. In 1972, at the Paris Summit, it was agreed that the Commission of the European Communities would develop an Environmental Action Programme, in order to outline the principles of EU policy towards the environment. However, the first explicit legal basis for EU environmental policy was provided, in 1987, under the Single European Act [1]. Within this Act, three major environmental priorities were identified, namely: 
- preservation, protection and improvement of the environment

- protection of human health

- prudent and rational utilization of natural resources.

The EU environmental policy objectives were further considered, in 1992, in the Treaty of European Union ("Maastricht Treaty"). Among others, it was recognized that economic development must be sustainable with respect to the environment. In addition, it was established that environmental protection should be integrated and implemented in other EU policies, preventive actions towards the protection of the environment should be applied, polluters should pay and benefits and costs of actions when preparing environmental policy actions should be taken into account [1]. In the same year, the Fifth Environmental Action Programme emphasized on the integration of the economy and the environment. This strategy marked a new era in the enforcement of EU environmental policy, promoting the use of the so-called market-based instruments. More specific, it was referred that "in order to get prices right and to create market-based incentives for environmentally friendly economic behaviour, the use of economic and fiscal instruments will have to constitute an increasingly important part of the overall approach" [2]. This philosophy was further strengthened, in 1993, by the White Paper on Growth, Competitiveness and Employment [3].

Though a very limited review of EU environmental policy is provided, it becomes evident that the role of economics towards a sound environmental policy within EU has risen. Especially during the last decade, there is a growing effort to incorporate monetary values in several areas and levels of decisionmaking processes (e.g. policies, regulations or projects). Towards this direction, the Laboratory of Mining and Environmental Technology (LMET) of the National Technical University of Athens (NTUA) has undertaken a research project aiming to develop a database of European valuation studies, called GEVAD (Greek Environmental Valuation Database), which will facilitate the application of environmental economics through the well-established Benefit Transfer (BT) method. The paper outlines some critical points of the integration of economics and the environment and illustrates the development of the GEVAD project, so far.

\section{Environmental policy instruments}

In general, given that an optimum level of pollution has been established, there are two principal types of environmental policy instruments to be followed: the so-called "command and control" and the "market-based" instruments.

The "command and control" approach sets specific environmental or emission standards that should be satisfied by the activities that may cause pollution. On the other hand, the "market-based" approach provides economic incentives (e.g. by imposing specific costs or taxes on polluting activities) that encourage polluters to reduce pollution, voluntarily. Hereinafter, the most common types of instruments are categorized according to OECD classifications [4] and Panayotou [5], as referred by Pearce and Howarth [6]. 


\section{A. Command and control instruments}

- ambient based standards (e.g. concentration of pollutants per $\mathrm{m}^{3}$ of air or $\mathrm{kg}$ of soil, etc.)

- emission based standards (e.g. $\mathrm{kg}$ of pollutants per $\mathrm{m}^{3}$ of flue gas emitted)

- product based standards (e.g. regulate, at an early stage of the production process, the firm's production technology or materials used)

- technology based standards (e.g. BATs)

- bans.

\section{B. Market-based instruments}

\section{Fiscal instruments}

- emission and effluent taxes (e.g. $\mathrm{SO}_{2}$ and $\mathrm{NO}_{\mathrm{x}}$ charge)

- input taxes (e.g. pesticides tax)

- final product taxes

- export taxes/import taxes

- differential taxation (e.g. leaded and unleaded gasoline)

- royalties

- subsidies (e.g. subsidies to renewable energy)

- tax relief measures.

Environmental charges

- user charges (e.g. entry fees to protected areas)

- betterment and impact charges (e.g. charges on properties which benefit from an environmental improvement or charges on properties for making the environment worse).

Deposits - refunds and performance bonds

Here the charge is made in advance of any damage occurring. Hence, refunds are given when the product is safely disposed of or recycled and bonds are only redeemed when restoration has taken place.

- deposit-refund schemes (e.g. on returnable cans)

- environmental performance bonds (e.g. for permitting mining or quarrying activities)

- accident bonds (e.g. for oil spills).

Tradable quotas and offsets

Quotas are related to emissions or resources. Offsets are referred to bargains between several parties, e.g. emission reduction obligation in one location is offset by reducing emission in another location.

- joint implementation (mainly $\mathrm{CO}_{2}$ emissions)

- emission permits $\left(\mathrm{CO}_{2}\right.$ and $\mathrm{SO}_{2}$ in the USA and $\mathrm{CO}_{2}$ in Europe)

- water use rights

- fishing quotas, etc.

Voluntary agreements

Voluntary agreements involve agreed environmental targets between government and industry such that industry "self regulates". 


\section{Liability measures}

Liability has certain similarities with bonds. Nevertheless, liability is applied only in the event of damage.

- legal liability (is "strict" when liability exists regardless of precautions taken, and is "fault-based" when actions taken to avoid damage are taken into account)

- non-compliance fines (penalties for emissions above standards)

- liability insurance.

Financial incentives

Financial incentives involve the creation of funds used for environmental improvements that may come from government grants, specific taxes, etc.

Property rights

Property rights should be secure (enforceable) and transferable for economic efficiency to be assured. Property rights can be private, communal or public, with a presumption that private and communal rights are to be preferred.

Information

- labelling (environmental labelling of products, resource contents, etc.)

- publication of environmental performance of industrial activities

- educational and training centres to stimulate environmental awareness.

\section{Environmental policy and valuation}

Environmental goods and services are "public goods" and, consequently, have no market price. This malfunction, known as "market failure", results in the socalled "externalities". The latter means that production activities create a social cost, which is not internalized in the traditional production cost.

In order to tackle with the problem, it is necessary to establish an effective environmental policy scheme. Nevertheless, when dealing with environmental policy issues, two principal questions arise:

- What is the optimal level of pollution?

- Which are the most suitable instruments to be applied in order to comply with acceptable levels of pollution?

Both questions have an economic origin and, thus, hold an economic dimension. As Freeman notes: "if society is to make the most of its cares resources, it should compare what it receives from pollution control and environmental protection activities with what it gives up by taking resources from other users. It should measure the values of what it gains (the benefits) and what it loses (the costs) in terms of the preferences of those who experience these gains and losses" [7]. In other words, the optimal environmental quality as well as the policy means required should be characterized by cost-effectiveness. Bearing in mind the above remarks, it becomes evident that estimation of environmental benefits and costs is required in environmental decision-making. Towards this direction, environmental valuation techniques play a significant role. Environmental valuation may be applied in different levels of decisionmaking process (i.e. policy, regulation and project appraisal), although may be 
used more frequently at one level than another. Further, it may be employed in both ex ante and ex post analyses.

The EU environmental policy context, driven by the increased prominence of sustainable development, emphasizes in market-based instruments especially in the last two decades. With respect to ex ante evaluation of policy and regulation making, the EU experience is limited compared to USA [8]. Nevertheless, there are certain examples towards this direction, such as the Clean Air For Europe (CAFE) Programme. Under the Sixth Environment Action Programme (EAP), "Environment Health and Quality of Life" is recognized as one of the four main target areas where new effort is needed. Air pollution is one of the issues included in this priority so as to achieve levels of air quality that do not give rise to unacceptable impacts on, and risks to, human health and the environment [9]. Within this strategy, the review and updating of air quality thresholds and national emission ceilings will take place. More specific, the two so-called "air quality daughter directives" (1999/30/EC and 2000/69/EC), as well as other relative legislation acts (e.g. the Directive on Large Combustion Plants) are due to be reviewed. As required by the Treaty, the policy will aim at a high level of environmental protection, taking account of the best available scientific and technical data and the costs or benefits of action or lack of action [10]. Towards this direction, CAFE has developed a methodology for the Cost-Benefit Analysis of air quality related issues [11]. On this basis, the European Commission proposes an ambitious strategy for achieving further significant improvements in air quality across Europe. The Strategy will reduce the number of premature deaths related to fine particulate matter and ozone from 370,000 per year in 2000 to 230,000 in 2020 . Based on the estimates, the Strategy will deliver health benefits worth at least $€ 42$ billion per year through fewer premature deaths, less sickness, fewer hospital admissions, improved labour productivity etc. This is more than five times higher than the cost of implementing the Strategy, which is estimated at around $€ 7.1$ billion per annum, or about $0.05 \%$ of EU-25 GDP in 2020 [12].

To date, the use of environmental valuation, although restricted to certain issues, is further encouraged by the legislation itself, at ex ante (e.g. permission processes) as well as ex post procedures (e.g. liability). For example, the IPPC (Integrated Pollution Prevention and Control) Directive 96/61/EC [13] lays down a framework requiring Member States to issue operating permits for certain installations. The importance of this Directive consists in the fact that these permits must contain conditions based on best available techniques (BAT) to achieve a high level of protection of the environment. According to the Article 2.11 of the Directive, "available" means those techniques developed on a scale which allows implementation in the relevant industrial sector, under economically and technically viable conditions and "best" means the most effective ones in achieving a high general level of protection of the environment as a whole.

The IPPC Directive gives clearly importance to the economic aspects of BATs. Within the framework of Article 16.2 of the IPPC Directive, the European IPPC Bureau (EIPPCB) organizes the exchange of information and produces 
BAT reference documents (BREFs), which Member States are required to take into account. Towards this direction, a horizontal BREF on "Economics and Cross-media Effects" has been developed, in order to assist in the determination of BAT under the IPPC Directive [14].

According to the methodology adopted by the abovementioned BREF, the results of the environmental cross-media assessment are compared to the costs of the available techniques (cost data for installing, operating and maintaining a process). Towards this direction, the approaches proposed are, as follows:

- Cost-effectiveness analysis

- Balancing costs and environmental benefits by means of:

- Reference prices

- External costs

Finally, an assessment of economic viability, when determining BATs at sector level, is required.

At the ex post regulatory level, the most characteristic example is the environmental damage liability. This issue has emerged since the early 70's, in the USA, when the Trans - Alaska Pipeline Authorization Act identified strict liability for damages from oil spills. The liability was extended beyond oil industry after the Congress enacted the Comprehensive Environmental Response, Compensation and Liability Act (CERCLA). The economic framework for estimating the non-market value of environmental resources was further processed by the Department of Interior [15] and it was strengthen, in 1989, by the U.S. Court of Appeals [16], which concluded that in performing detailed assessments, the trustee is allowed to measure environmental damages according to "use values" rather than clean-up costs, in cases where the costs to restore the area is "grossly disproportionate" to its "use value".

In 1993, the European Commission published the Green Paper on Remedying Environmental Damage [17]. In 2000, the European Commission adopted a White Paper on Environmental Liability [18]. Its objective was to explore how the polluter pays principle could best be applied to serve the aims of Community environmental policy. In January 2002, the Commission adopted a legislative proposal for a Directive and, finally, in 2004, the Directive 2004/35/EC on environmental liability with regard to the prevention and remedying of environmental damage was published [19]. The objective of this Directive is "to establish a common framework for the prevention and remedying of environmental damage at a reasonable cost to society". Though a detailed discussion goes beyond the scope of this paper, the proposed valuation approach in the Directive relies basically on the restoration costs, which are easier and cheaper to estimate than monetary estimates of the value of natural resources. In relation to the use of environmental valuation, it is referred in Annex II, Sec. 1.2.3 that "If it is not possible to use the first choice resource-to-resource or service-to-service equivalence approaches, then alternative valuation techniques shall be used. The competent authority may prescribe the method, for example monetary valuation, to determine the extent of the necessary complementary and compensatory remedial measures. If valuation of the lost resources and/or services is practicable, but valuation of the replacement natural resources and/or 
services cannot be performed within a reasonable time-frame or at a reasonable cost, then the competent authority may choose remedial measures whose cost is equivalent to the estimated monetary value of the lost natural resources and/or services". Yet, the European framework for estimating the non-market value of environmental resources is less supportive, compared to USA.

As far as project appraisal is concerned, guidelines for the valuation of environmental impacts by means of cost benefit analysis (CBA) can be found in USA manuals for water projects, recreational use of forested areas, etc. [8]. In Europe, the history of environmental valuation in CBA is much shorter and the existence of such guidelines is quite limited [8]. Manuals for CBA can be found in a few European countries mainly for transportation projects, but most often they do not provide guidelines for economic valuation of environmental impacts [20]. According to Bonnieux and Rainelli [20], the limited role of environmental valuation in project appraisal, besides other obstacles (e.g. philosophical, political or ethical reasons) referred by Barde and Pearce [21], is also attributed to the environmental impact assessment (EIA) Directive 85/337. The latter has no requirement for the valuation of the environmental impacts caused by the projects under investigation. To date, however, there are some cases in which the absence of a cost benefit analysis has resulted in the cassation of projects (e.g. Decision Record 613/2002 of the Greek State Council with respect to a significant gold mining project in Northern Greece), although the competent authorities had approved the EIA statement.

\section{The GEVAD project}

Given the increasing desire for incorporating monetary values in public decisionmaking, environmental valuation methods are applied at a growing rate in Europe. So far, several studies have been carried out, particularly in UK, Germany, Scandinavian countries and the Netherlands. Especially in the field of practical policy analysis, however, studies carried out by means of the Benefit Transfer (BT) method are normal practice as only rarely, policy analysts can afford to design and implement original studies, given the high costs and efforts of administering an original valuation study [22]. Further, for countries with limited experience in performing primary valuation studies, the BT technique might, in some instances, be the preferred valuation method [23].

According to Desvousges et al. [24] and Rosenberger and Loomis [25] necessary conditions for performing a successful transfer study, besides the quality of the original study, are:

- the studied good/service of the original valuation study and the new study are similar to great extent

- the aspect to be valued in the new study is similar to that in the original study

- the socio-demographic characteristics of the relevant population groups are similar.

Reaching a satisfactory degree of reliability in BT application prerequisites having access to a large number of original studies. So far, two tools are well 
known: the EVRI (Environmental Valuation Reference Inventory) and the ENVALUE databases [26, 27]. These two tools can be searched by environmental attribute valued, valuation technique used, location etc, so as to identify the most relevant primary studies. However, according to Navrud and Vågnes [26], by 2000, only 56 out of the more than 650 European Valuation studies were recorded in EVRI, which corresponds to less than $10 \%$.

A relative project, namely GEVAD (Greek Environmental Valuation Database), which is co-funded by the European Social Fund and National Resources, is being carried out by the LMET of the NTUA. The tool will provide the necessary data to value environmental impacts of industrial activities in Greece and other European countries, based on BT method in compliance with the institutional and research context of the international scientific community. The prescribed actions of this project include literature review of a large number of studies, codification and adjustment to the particular characteristics of European space using suitable techniques and development of a software to guide the users. The GEVAD tool will be completed till the end of 2006. By that time, approximately 400 studies will have been registered. To date, 1200 studies have been tracked and 1017 from them are selected to be reviewed in the next phase, focusing on the ones that are spatially and temporally more relevant to Greece and Europe, in general. Indicatory of the emphasis given on the most recent research is the fact that $42.9 \%$ of the studies selected were conducted in the last five years and almost $75 \%$ in the last ten years. Additionally, $57.0 \%$ of the recorded studies concern Europe, filling the gaps of the databases mentioned. Studies will be classified in GEVAD according to the environmental asset, good or service, which is valued (e.g. amenities, water and air quality, land contamination, etc.), method used, etc. The GEVAD will provide, by means of a user-friendly environment, interactive "environmental valuation" estimates through the Internet. The database will be searchable and will also include specific tools, e.g. adjustments for the spatial dimension and the temporal dimension of the transferred values.

\section{Discussion}

From the analysis presented, it becomes evident that, although at the very beginning, the use of environmental valuation plays already an important role and it will become a decisive basis for the environmental policy in the "era of economics". This will enhance a wider use of cost benefit analysis and, consequently, one will need to apply monetary valuation techniques for public decision-making processes. However, the objective to keep administration costs as low as possible cannot be neglected. Since original valuation studies are both costly and time-consuming, it is often more efficient, at least for some cases, to use transferred estimates. Towards this direction, it is necessary to establish a pool of original studies, covering as many environmental themes as possible. So far, EVRI and ENVALUE databases are the most known and easily accessible ways to locate studies for a benefit transfer. Yet, there is a need to expand their coverage to the EU countries. The GEVAD project aims to close this gap by 
gathering a critical mass of recent EU valuation studies. In this way, an information centre that will collect, classify and disseminate environmental valuation data is to be established, providing the means for facilitating the application of environmental valuation in Greece and other European countries.

\section{Acknowledgments}

This study has been undertaken by the GEVAD Project, which is co-funded by the European Social Fund (75\%) and National Resources (25\%) - Operational Programme for Educational and Vocational Training (EPEAEK II)PYTHAGORAS.

\section{References}

[1] Clinch, P., Environmental Policy Reform in the EU, Working Paper, University College Dublin, 1999.

[2] European Environment Agency, Environment in the European Union at the Turn of the Century, Office of Official Publications of the European Communities, Luxemburg, 1999.

[3] European Commission, White Paper on growth, competitiveness, and employment: The challenges and ways forward into the 21st century, COM (93) 700 final, Brussels, 1993.

[4] OECD, Managing the Environment: the Role of Economic Instruments, Paris, 1994.

[5] Panayotou, T., Economic Instruments for Environmental Management and Sustainable Development, Environmental Economics Series Paper No. 16, Environment and Economics Unit, United Nations Environment Programme, Nairobi, 1994.

[6] Pearce, D. and Howarth, A., Technical Report on Methodology: Cost Benefit Analysis and Policy Responses, RIVM report 481505020, National Institute of Public Health And The Environment, 2000.

[7] Freeman III, A.M., The Measurement of Environmental and Resource Values, Resources for the Future, Washington DC, 1993.

[8] Navrud, S. and Pruckner, G., Environmental Valuation - To Use or Not to Use? Environmental and Resource Economics, 10, pp. 1-26, 1997.

[9] European Commission, Decision No 1600/2002/EC of the European Parliament and of the Council of 22 July 2002 laying down the Sixth Community Environment Action Programme, Official Journal of the European Communities, 242, 2002.

[10] European Commission, Communication from the Commission, The Clean Air for Europe (CAFE) Programme: Towards a Thematic Strategy for Air Quality, COM 245, 2001.

[11] AEA Technology Environment, Methodology for the Cost-Benefit analysis for Café, Vol. 1: Overview of the Methodology, UK, 2005.

[12] European Commission, Commission proposes clean air strategy to protect human health and the environment, Press release, IP/05/1170, 2005. 
[13] European Commission, Council Directive 96/61/EC of 24 September 1996 concerning 'Integrated pollution prevention and control', Official Journal of the European Union, L 257, 1996.

[14] European Commission, Reference Document on Economics and CrossMedia Effects, DG JRC, European IPPC Bureau, 2005.

[15] U.S. Department of Interior - DOI. Natural Resource Damage Assessments: Final Rule, DOI, Office of Secretary, 43 CFR Part 11, Federal Register 51, No. 1148: 27673 - 27753, 1986.

[16] U.S. Court of Appeals, District of Columbia. Ohio vs. United States Department of Interior, 880 F.2d 432, 19 ELR 21099, 1989.

[17] European Commission, Green Paper on remedying environmental damage, COM 47 final, 1993.

[18] European Commission, White paper on environmental liability, COM 66 final, 2000.

[19] European Commission, Directive 2004/35/EC of the European Parliament and of the Council of 21 April 2004 on environmental liability with regard to the prevention and remedying of environmental damage, Official Journal of the European Union, L 143, 2004.

[20] Bonnieux, F. and Rainelli, P. Contingent valuation methodology and the EU institutional framework. Valuing environmental preferences, Theory and practice of the contingent valuation method in the US, EU and Developing Countries, (eds.) Bateman, I.J., Willis, K.G., Oxford University Press, New York, 585-612, 1999.

[21] Barde, J. P. \& Pearce, D.W., Valuing the Environment: Six Case Studies, Earthscan, London, 1991.

[22] Desvousges, W.H., Johnson, F.R., Banzhaf, H.S., Environmental policy analysis with limited information. Principles and applications of the transfer method, Cheltenham, Edward Elgar, 1998.

[23] Ellen Moons, The development and application of economic valuation techniques and their use in environmental policy - A survey, Energy, Transport and Environment Working Papers Series, ete0307, Katholieke Universiteit Leuven, Centrum voor Economische Studiën, Energy, Transport and Environment, 2003.

[24] Desvousges, W.H., Naughton, M.C., Parsons, G.R. Benefit transfer: Conceptual problems in estimating water quality benefits using existing studies. Water Resources Research. 28(3):675-683, 1992.

[25] Rosenberger, R.S. Loomis, J.B. Benefit transfer of outdoor recreation use values: A technical document supporting the Forest Service Strategic Plan, (2000 revision). Gen. Tech. Rep. RMRS-GTR-72. Fort Collins, CO: U.S. Department of Agriculture, Forest Service, Rocky Mountain Research Station, 2001.

[26] Navrud, S. and Vågnes, M. Assessment of Environmental Valuation Reference Inventory (EVRI) and the Expansion of Its Coverage to the EU, 2000, http://europa.eu.int/comm/environment/enveco/studies2.htm\#24. 